\title{
DAMPAK ON-THE-JOB TRAINING DI LUAR NEGERI PADA STRATEGI PEMBELAJARAN BAHASA INGGRIS DAN KEMAMPUAN SOFT SKILLS MAHASISWA
}

\author{
Kun Aniroh \\ Email: anir_kun@yahoo.com \\ Program Diploma IV Perhotelan Universitas Merdeka Malang \\ Alamat Korepondensi: Jalan Tirtotaruno Gang 5/20 Landungsari Malang 65151
}

\begin{abstract}
Globalization opens up the chances for students of hotel studies to have on-the-job training at hotels abroad with the duration of six months up to one year. At the first three months the students got difficulties in using their English and get less interaction and appropriate behavior because in a hotel abroad there are many staffs from many countries using English with different accents and different cultures. Such environment triggered students to learn English with a particular strategy that lead them to improve their English and their soft skills convincingly.
\end{abstract}

\section{Keywords}

On-The-Job Training, Bahasa Inggris, Strategi, Soft Skills

\section{Pendahuluan}

Salah satu ciri globalisasi adalah perpindahan tenaga kerja dari suatu negara ke negara lain sehingga di samping dituntut untuk menguasai ilmu dan teknologi yang berstandar internasional, tenaga kerja dituntut pula menguasai bahasa internasional sebagai alat komunikasi. Menurut Tilaar (1998:27), dalam menghadapi perdagangan bebas kemampuan komunikasi para ilmuwan dan mahasiswa harus sudah diantisipasi di dalam program kurikulum pendidikan tinggi nasional. Ini berarti bahwa penguasaan bahasa-bahasa seperti bahasa Inggris, bahasa Mandarin dan bahasa Jepang di dalam perdagangan dan pergaulan internasional harus dikuasai dengan baik. Kemampuan merumuskan dan menyampaikan bidang ilmu masing-masing baik itu dalam bahasa Indonesia maupun bahasa asing harus dikuasai, ditambah dengan penguasaan bahasa komputer atau bahasa digital (IT literate) di mana bidangbidang strategis seperti: bisnis, teknologi dan industri wisata pada umumnya memerlukan penguasaan bahasa Inggris yang memadai untuk komunikasi internasional.

Secara lebih rinci Napitupulu (1998:58) mengemukakan bahwa dalam era globalisasi siapa pun terutama para mahasiswa hendaknya dapat memanfaatkan informasi yang lalu lalang di angkasa, dan diusahakan dengan sungguh-sungguh agar para mahasiswa Indonesia bisa "go bilingual", yaitu menguasai bahasa Indonesia dan bahasa Inggris agar tidak dihanyutkan arus globalisasi.
Tambusai (2000:12) menyatakan bahwa untuk menjadi tenaga kerja yang mampu bersaing di pasar global harus memiliki sikap mental dan attitude yang kompetitif, penguasaan keahlian dan ketrampilan, kemampuan berbahasa asing minimal bahasa Inggris dan penguasaan teknologi digital (komputer dan internet). Jika dihubungkan dengan faktor-faktor persaingan yang terdiri dari ekonomi domestik, internasionalisasi, pemerintahan, keuangan, infrastruktur, manajemen, ilmu pengetahuan, teknologi dan sumberdaya manusia, secara umum Indonesia belum mendapatkan peringkat yang memadai bahkan diantara negaranegara ASEAN sekali pun sumber daya manusia masih memiliki HDI (human development index) yang dapat dikatakan rendah. Bila dibandingkan dengan negara lain di ASEAN, Malaysia berada di urutan 57 dan Filipina di urutan 89 sedangkan Indonesia berada di urutan 108 dari 169 negara di dunia (UNDP, 2010). Kondisi semacam ini merupakan tantangan untuk bersaing dengan sumber daya manusia dari bangsa lain. Hal yang demikian ini mendorong perlunya dilakukan peningkatan kualitas sumberdaya manusia melalui kurikulum dan proses belajar mengajar yang proaktif yang dapat menghasilkan tenaga yang profesional dibidangnya, berinovasi dan mampu di bidang ilmu pengetahuan dan teknologi (Taufik, 1998:106) 


\section{Penutup}

On-the-job training ke luar negeri antar 6 bulan sampai satu tahun, ternyata mampu meningkatkan kamampuan berbahasa Inggris. Dari hasil nilai bahasa Inggris yang berupa dokumen nilai bahasa Inggris pada saat sebelum berangkat on the job training dan sesudah pulang dari on-the-job training, mayoritas mahasiswa mengalami peningkatan kemampuan dalam berbahasa Inggris. Strategi belajar yang telah mereka gunakan di luar kelas yaitu dorongan untuk terus belajar, belajar dengan trial and error dengan tamu, belajar reading dan vocabulary dari form-form atau borang di outlet, belajar listening dan speaking dari coworkers pada saat bekerja, belajar listening, speaking, pronuciation dari tamu dan dalam waktu senggang minta diajari oleh tamu berperan besar dalam meningkatkan kemampuan berbahasa Inggris para trainee. Selain itu, on the job training ke luar negeri selama antara 6 bulan sampai satu tahun juga mampu meningkatan kemampuan soft skills mereka. Hal-hal yang menonjol dalam penjabaran peningkatan soft skills adalah sebagian besar mampu bekerja secara terus, yaitu tahan bekerja selama 12 jam, bisa lebih mengontrol emosi, tetap tersenyum walau kerja berat, berani menghadapi tamu, didiplin dalam waktu, lebih percaya diri, penampilan menjadi lebih baik, dan secara keseluruhan kemampuan berbahasa yang juga merupakan salah satu kemampuan dalam soft skills juga meningkat.

Berdasarkan temuan-temuan tersebut di atas beberapa pihak baik itu lembaga pendidikan, maupun industri, atau pendidik seyogyanya perlu melakukan hal-hal sebagai berikut:

Pertama, memberi kesempatan belajar bahasa Inggris dengan suasana budaya yang beragam baik di dalam maupun di luar negeri. Selain itu, menyisipkan soft skills dalam mata kuliah bahasa Inggris atau mata kuliah lain baik itu dalam bentuk tugas kelompok, individu maupun tugas proyek yang bisa menonjolkan soft skills seseorang.

Kedua, yang perlu dilakukan adalah menganjurkan para pengajar di pendidikan diploma khususnya dan di tingkat pendidikan mana pun pada umumnya terus menerus belajar soft skills agar terjadi keseimbangan kemampuan kognitif dan afektif. Selain itu, mahasiswa perlu mengasah secara terus menerus kemampuan soft skills pada saat dalam pendidikan, pada saat sudah bekerja maupun dalam kehidupan sehari-hari karena pada hakekatnya belajar apapun termasuk soft skills adalah life-long learning.

Ketiga, mahasiswa perlu mendapatkan contoh atau suri tauladan, kedisiplinan, integritas, sikap yang positif dan konsisten serta sifat dan sikap positif lainnya dari pengajar sehingga akan tercipta pembentukan karakter yang kuat. Pengajar hendaknya juga menjadi pendidik yang mampu memberikan nilai-nilai kedisiplinan, kejujuran, kegigihan, mampu menumbuhkan rasa percaya diri, ramah dan mampu menerapkan sifat-sifat tersebut dalam dirinya baik di dalam kelas maupun di luar kelas. 


\section{DAFTAR PUSTAKA}

Cahyono, B.Y. 1997. Pengajaran Bahasa Inggris, Teknik Strategi, dan Hasil Penelitian. Malang: Penerbit IKIP Malang.

Creswell, J.P. 1994. Research Design: Qualitative and Quantitative Approaches. Thousand Oaks. California: Sage Publication.

Forcheri, P., Molfino, M.T., Van Diepen, N., Nova, E.S, Sendova, E. 2007. Giving Teachers a Hand(book) to Develop ICT-Enhanced Skills. Proceedings of the 3rd Balkan Conference in Informatics (BCI 2007).

Napitupulu, W.P. 1998. Kondisi Mutu Pendidikan Tinggi di Negara-negara Asia Pasifik. Makalah disampaikan dalam Seminar Membangun Daya Saing Bangsa Melalui Akselerasi Mutu Pendidikan Tinggi, Malang: Merdeka University Press.

Rao, M.S. 2010. How to Improve Soft Skills. Career Journal.com 30-3-2010.

Sailah, I. 2008. Pengembangan Soft Skills di Perguruan Tinggi. Tim Pengembang Soft Skills dan KBK-DIKTI.

Shah, N.Z. 2008. Are Graduates to be Blamed? Unemployment of Computer Science Graduates in Malaysia. Electronic Journal of the American Association of Behavioral and Social Sciences. Vol. 11.

Shakespeare, P., Keleher, P and Moxham, L. 2007. Soft skills, Hardskills and Practice Identity. World Conference on Cooperation Education, Transcending Boundaries. Work-Integrated Learning for the Global Economy, Suntec International Convention and Exhibition Center, Singapore 26 th-27th June, 2007.

Tambusai, H. 2000. Penyetaraan Kualitas TKI. Makalah disampaikan dalam Sarasehan Menangkap Peluang Kerja di Luar Negeri di Universitas Negeri Malang 20 September 2000.

Taufik, I. 1998. Peningkatan Daya Saing Alumi Perguruan Tinggi Melalui Strategi Penyusunan Kurikulum dan Proses Belajar Mengajar Proaktif. Makalah disampaikan dalam Seminar Membangun Daya Saing Bangsa Melalui Akselerasi Mutu Pendidikan Tinggi, Malang: Merdeka University Press.

Tilaar, H.A.R. 1998. Pendidikan Tinggi di Indonesia Dewasa Ini Menghadapi Tantangan Abad XXI. Disampaikan dalam Seminar Membangun Daya Saing Bangsa Melalui Akselerasi Mutu Pendidikan Tinggi. Malang: Merdeka University Press.

UNDP. 2010. 'Explanation Note on 2010 HDR Indices: Indonesia'. http://hdrstats.undp.org/images/explanations/IDN.pdf

Urchiuoli, B. 2008. Skills and Selves in the New Workplace. American Ethnologist, Volume 35, Issues 2, pp 211228.

Williams, B., dan Figueiredo, J. 2007. Communication Outcomes in Bologna: An Appropriate to Professional English for Engineering Students. Proceeding of the 4th WSEA/IASME International on Engineering Education, July 24-26, 2007. 